\title{
Intrahepatic cholangiocarcinoma: current perspectives
}

\author{
This article was published in the following Dove Press journal: \\ OncoTargets and Therapy \\ 22 February 2017 \\ Number of times this article has been viewed
}

\author{
Stefan Buettner \\ Jeroen LA van Vugt \\ Jan NM IJzermans \\ Bas Groot Koerkamp \\ Department of Surgery, Erasmus MC \\ University Medical Center, Rotterdam, \\ the Netherlands
}

\begin{abstract}
Intrahepatic cholangiocarcinoma (ICC) is the second most common malignancy arising from the liver. ICC makes up about $10 \%$ of all cholangiocarcinomas. It arises from the peripheral bile ducts within the liver parenchyma, proximal to the secondary biliary radicals. Histologically, the majority of ICCs are adenocarcinomas. Only a minority of patients (15\%) present with resectable disease, with a median survival of less than 3 years. Multidisciplinary management of ICC is complicated by large differences in disease course for individual patients both across and within tumor stages. Risk models and nomograms have been developed to more accurately predict survival of individual patients based on clinical parameters. Predictive risk factors are necessary to improve patient selection for systemic treatments. Molecular differences between tumors, such as in the epidermal growth factor receptor status, are promising, but their clinical applicability should be validated. For patients with locally advanced disease, several treatment strategies are being evaluated. Both hepatic arterial infusion chemotherapy with floxuridine and yttrium-90 embolization aim to downstage locally advanced ICC. Selected patients have resectable disease after downstaging, and other patients might benefit because of postponing widespread dissemination and biliary obstruction.
\end{abstract}

Keywords: intrahepatic cholangiocarcinoma, diagnosis, treatment, developments

\section{Incidence and risk factors}

The incidence of intrahepatic cholangiocarcinoma (ICC) in the Western world is approximately one to two per $100,000 .{ }^{1-3}$ ICC is the second most common malignancy arising from the liver, accounting for $3 \%$ of all cases of gastrointestinal cancer. ${ }^{4,5}$ ICC makes up about $10 \%$ of all cholangiocarcinomas. It arises in peripheral bile ducts within the liver parenchyma, proximal to the secondary biliary radicals (Figure 1). ${ }^{6}$ It should be distinguished from perihilar cholangiocarcinoma arising near the biliary confluence and distal cholangiocarcinoma arising near the head of the pancreas. Only a minority (15\%) of ICC patients present with resectable disease at the time of diagnosis. Complete surgical resection remains the only option for cure with an estimated median survival ranging from 27 to 36 months (Figure 2). ${ }^{5,7-10}$

Over three-quarters of patients are older than 65 years at initial diagnosis, ${ }^{3}$ and ICC is slightly more common in men. ${ }^{11}$ ICC is more common in East Asia; in the People's Republic of China, an incidence of 10 per 100,000 persons has been reported, while in Thailand, the incidence is 71 per 100,000, higher than for hepatocellular carcinoma (HCC). ${ }^{1,12}$

In general, ICC has similar risk factors to HCC. A correlation with diseases causing biliary inflammation and fibrosis, such as primary sclerosing cholangitis and primary biliary cirrhosis, has been noted. ${ }^{13,14}$ Other risk factors for ICC are congenital
Correspondence: Bas Groot Koerkamp Department of Surgery, Erasmus MC University Medical Center, 's-Gravendijkwal 230, Room H-809, 3015 CE Rotterdam, the Netherlands Tel +31 107031810

Email b.grootkoerkamp@erasmusmc.nl (c)
hereby accept the Terms. Non-commercial uses of the work are permitted without any further permission from Dove Medical Press Limited, provided the work is properly attributed. For permission hereby accept the Terms. Non-commercial uses of the work are permitted without any further permission from Dove Medic
for commercial use of this work, please see paragraphs 4.2 and 5 of our Terms (https://www.dovepress.com/terms.php). 


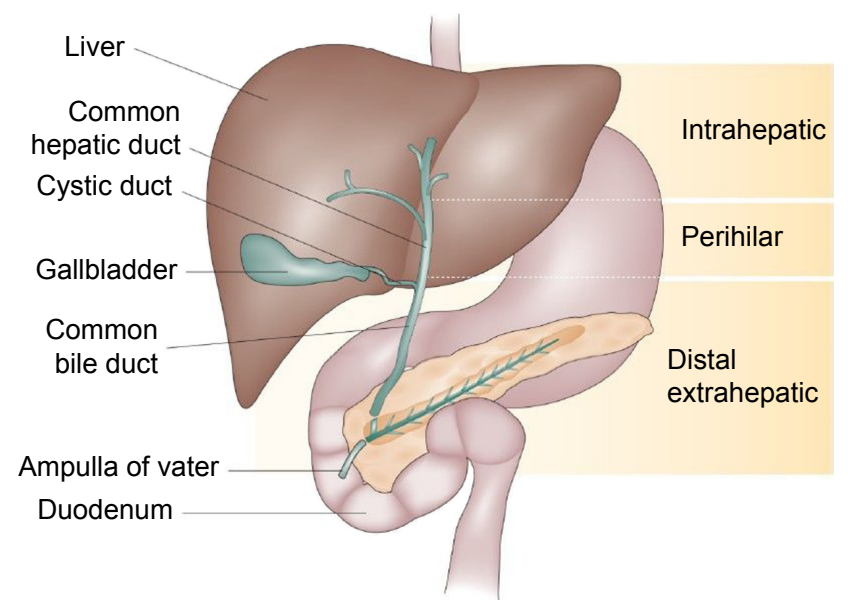

Figure I Types of cholangiocarcinoma.

Note: Adapted by permission from Macmillan Publishers Ltd: Nat Rev Gastroenterol Hepatol. Blechacz B, Komuta M, Roskams T, Gores GJ. Clinical diagnosis and staging of cholangiocarcinoma. 20II;8(9):5I2-522. Copyright 201 I. ${ }^{134}$

malformations of the bile duct (ie, choledochal cysts), hepatolithiasis, hepatitis $\mathrm{B}$ and $\mathrm{C}$ virus, alcoholic liver cirrhosis, and smoking. ${ }^{13}$ In East Asia, hepatic parasite infections, in particular Opisthorchis viverrini and Clonorchis sinensis, are significant risk factors. ${ }^{15,16}$ The reason for the vast difference in incidence between the east and west is not fully understood, as it cannot be attributed completely to the spread of the infectious risk factors. ${ }^{1,12}$

\section{Histology}

ICC mostly develops as a well-differentiated adenocarcinoma. ${ }^{17,18}$ Its formation is frequently caused by mutations of the KRAS oncogene, a protein normally involved

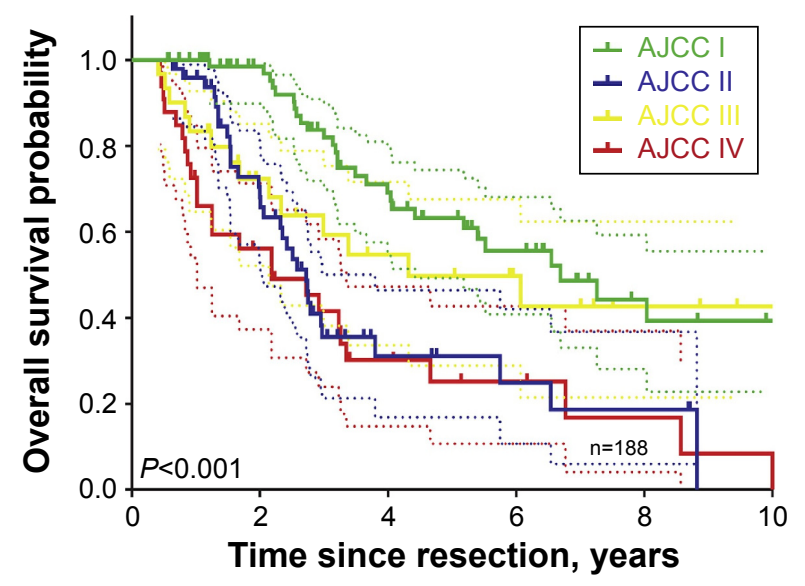

Figure 2 Overall survival in a large cohort of intrahepatic cholangiocarcinoma patients.

Note: Reprinted from L Am Coll Surg, 22I(2), Doussot A, Groot-Koerkamp B, Wiggers JK, et al., Outcomes after resection of intrahepatic cholangiocarcinoma: external validation and comparison of prognostic models, 452-46I, Copyright (20I5), with permission from Elsevier. ${ }^{44}$

Abbreviation: AJCC, American Joint Committee on Cancer Staging. in the cell proliferation, in combination with the deletion of the $\mathrm{p} 53$ tumor suppressor gene. ${ }^{19} \mathrm{~A}$ critical signaling protein downstream of KRAS and 533 mutations is interleukin (IL) 6 , which is a serum biomarker for ICC. ${ }^{20-22}$ Further downstream, ROS1 fusion proteins, regulated by KRAS/IL-6 pathways, have been associated with an aggressive phenotype and metastatic disease at diagnosis. ${ }^{23,24}$

Based on their histological appearance, ICCs can be divided into three histological growth types: the mass-forming, intraductal infiltrating, and periductal pattern. ${ }^{25,26}$ The most common of these growth patterns is the mass-forming pattern, of which the clinical symptoms may be similar to HCC as both involve the formation of a mass in the liver. ${ }^{27,28}$ On imaging (ie, computed tomography $[\mathrm{CT}]$ and magnetic resonance imaging $[\mathrm{MRI}]$ ), these tumors are clearly visible and well delineated. ${ }^{26}$ Mass-forming ICC typically has a diameter of 5-10 $\mathrm{cm}$ at the time of diagnosis. ${ }^{29,30}$ Intraductal ICC is a slowly growing papillary tumor and has a favorable prognosis compared with the other two types..$^{26}$ On imaging, it is a $1-2 \mathrm{~cm}$ mass within the bile duct with proximal ductal dilatation. The mass is usually confined to the bile duct wall. ${ }^{26,31,32}$ Periductal infiltrating cholangiocarcinoma is characterized by growth along the bile duct without mass formation, which radiologically presents as a small lesion or diffuse bile duct thickening. ${ }^{33}$ This type of tumor is a rare form of ICC and is commonly seen in combination with massforming ICC. ${ }^{34,35}$ The different histological appearances of cholangiocarcinoma necessitate different surgical strategies, since tumors growing along the bile duct (intraductal and periductal ICC) often require extrahepatic bile duct resection in addition to hepatic resection. ${ }^{26,36}$

ICC and HCC may occur simultaneously in the same patient or even in the same lesion. ${ }^{37,38}$ Combined HCC and ICC tumors mostly follow the more aggressive behavior of ICC. ${ }^{37}$ Because of similar allelic losses in both HCC-like and ICC-like cells, these tumors are thought to have a monoclonal origin with bidirectional phenotype differentiation. ${ }^{38,39}$ In concordance with this hypothesis, a Korean group recently suggested that the acquisition of ICC characteristics is a leading cause of atypically aggressive $\mathrm{HCC}$ behavior. ${ }^{40}$ Further research in the fields of imaging and molecular analysis is required to improve early diagnosis. ${ }^{38}$

\section{Staging}

The most commonly used classification system to qualify advancement and resectability of ICC is the American Joint Committee on Cancer (AJCC) TNM staging system, currently in its seventh edition, consisting of four stages 
Table I American Joint Committee on Cancer TNM classification, seventh edition

\begin{tabular}{|c|c|}
\hline TNM stage & Definition \\
\hline \multicolumn{2}{|l|}{ T stage } \\
\hline Tx & No description of the tumor's extent is possible because of incomplete information \\
\hline T0 & There is no evidence of a primary tumor \\
\hline \multirow[t]{2}{*}{ TI } & There is a single tumor that has grown into deeper layers of the bile duct wall, but it is still only in the bile duct. \\
\hline & The cancer has not grown into any blood vessels \\
\hline $\mathrm{T} 2 \mathrm{a}$ & There is a single tumor that has grown through the wall of the bile duct and into a blood vessel \\
\hline $\mathrm{T} 2 \mathrm{~b}$ & There are two or more tumors, which may (or may not) have grown into blood vessels \\
\hline T3 & $\begin{array}{l}\text { The cancer has grown into nearby structures such as the intestine, stomach, common bile duct, abdominal wall, } \\
\text { diaphragm (the thin muscle that separates the chest from the abdomen), or lymph nodes around the portal vein }\end{array}$ \\
\hline T4 & The cancer is spreading through the liver by growing along the bile ducts \\
\hline \multicolumn{2}{|l|}{ N stage } \\
\hline $\mathrm{Nx}$ & Nearby (regional) lymph nodes cannot be assessed \\
\hline No & The cancer has not spread to nearby lymph nodes \\
\hline $\mathrm{NI}$ & The cancer has spread to nearby lymph nodes \\
\hline \multicolumn{2}{|r|}{ 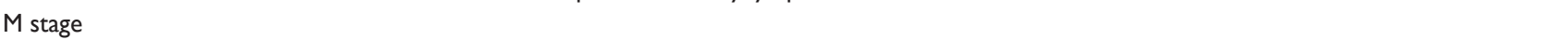 } \\
\hline Mo & The cancer has not spread to tissues or organs far away from the bile duct \\
\hline MI & The cancer has spread to tissues or organs far away from the bile duct \\
\hline \multicolumn{2}{|c|}{ Stage grouping } \\
\hline Stage I & TI, NO, MO \\
\hline Stage II & T2, No, MO \\
\hline Stage III & T3, No, MO \\
\hline Stage IVa & T4, N0, Mo/any T, NI, MO \\
\hline Stage IVb & Any $\mathrm{T}$, any $\mathrm{N}, \mathrm{MI}$ \\
\hline
\end{tabular}

(Table 1). ${ }^{41}$ Prior to this edition, there was no separate staging system for ICC, and these tumors were classified with HCC. ${ }^{42}$ The T-stage is determined by the number of liver tumors, the presence of vascular invasion, and direct extrahepatic invasion. The T4 stage is reserved for tumors with a periductal growth pattern. N1 indicates the presence of regional lymph node metastases, and M1 indicates distant metastases. ${ }^{42}$ Recent research suggests the AJCC staging system performs poorly in differentiating between various prognoses, with vast inter-patient survival differences within TNM stages. ${ }^{43,44}$ Additional independent prognostic factors have been identified to improve staging, including elevated serum carbohydrate antigen (CA) 19-9 and carcinoembryonic antigen (CEA), lympho(neuro)vascular invasion, and serum alkaline phosphatase (ALP). ${ }^{44}$

A genomic biomarker profile can also help in differentiating patients with ICC. ${ }^{45-47}$ A genomic study of 149 patients with ICC identified two molecular subgroups, an inflammation and a proliferation group, with distinct clinical outcomes. The inflammation subclass (40\%) showed increased activation of inflammation pathways, overexpression of IL-6, IL-10, and IL-17, and constitutive activation of immune system transcription factor STAT3. ${ }^{47,48}$ The proliferation subclass $(60 \%)$ showed increased activation of oncogenic pathways RAS/MAPK and MET, specific DNA mutations, and risk factors for poor clinical outcome. ${ }^{13,48}$
In a recent meta-analysis, we identified several immunohistochemistry biomarkers for patients with ICC. ${ }^{45}$ An example of a diagnostic and prognostic biomarker is fascin, an actin cross-linked protein found in the cell membrane of the biliary duct cells. ${ }^{49}$ The epidermal growth factor receptor also plays an important role in prognostics and is a potential treatment target. ${ }^{50,51}$ Mucin 1, cell surface associated and Mucin 4, cell surface associated are two membrane proteins that have been shown to be associated with patient prognosis. ${ }^{52-54}$ Lastly, p27, cyclin-dependent kinase inhibitor $1 \mathrm{~B}$, is a protein involved in the cell cycle, which also has predictive capabilities in relation to postoperative survival. ${ }^{55-57}$ In addition to these biomarkers, several other biomarkers have been shown to have an impact on diagnostics, prognostics, and treatment efficacy: HSP27; Akt; HDGF; Mucin 6, cell surface-associated; p16; p-4EBP1; S100A4; alpha-SMA; keratin 903; and TROP2. ${ }^{45}$ A composite biomarker profile could improve prognosis and guide treatment selection. ${ }^{47}$

\section{Diagnosis and preoperative workup}

The initial diagnosis of ICC is mostly made when the tumor is not eligible for resection because of locally advanced or metastatic disease. ${ }^{13,14,58}$ Typically, a very large mass has developed in the periphery of the liver with few clinical symptoms. ${ }^{19}$ Most patients present with nonspecific symptoms, such as pain in the right upper abdominal quadrant, 
weight loss, and high serum ALP levels. Some patients present with painless jaundice, when the tumor grows towards the biliary confluence. ${ }^{14,58}$ Small ICCs are found in screening programs for early detection of HCC. ${ }^{59}$

Transabdominal ultrasound is often the first imaging modality that detects a liver mass with or without dilatation of the biliary tract. ${ }^{60}$ The number of lesions and vascular involvement are determined using a dual-phase multi-detector CT. Typical appearance of ICC on CT is a hypodense mass with irregular margins on unenhanced scans, peripheral rim enhancement in the arterial contrast-enhancement phase, and progressive contrast uptake in the (portal-)venous and delayed contrast-enhancement phase. ${ }^{61}$ Small ICCs can be difficult to distinguish from HCC. Biliary drainage (if needed) should be performed after imaging because the presence of stents and drains hampers accurate assessment of the extent of the tumor. ${ }^{62}$

Both magnetic resonance cholangiopancreatography (MRCP) and positron emission tomography (PET) have a good accuracy for diagnosis and assessment of the extent of the tumor. MRCP has a diagnostic accuracy of up to $93 \%$ and is recommended for visualization of the tumor extension in the ductal system and vascular structures. ${ }^{47,63}$ Clinical utility of PET for diagnosing ICC in the liver when CT or MRI has been performed is limited. ${ }^{47}$ However, preoperative PET scanning may be considered to help rule out occult metastatic disease, as PET changes surgical decision making in up to $30 \%$ of patients. ${ }^{64-66}$ Despite these imaging modalities, as many as a third of patients with resectable disease on imaging have occult metastatic or locally advanced disease during diagnostic laparoscopy. ${ }^{67,68}$ Therefore, better imaging is needed to avoid surgery in these patients..$^{14,67,68}$

\section{Biliary drainage and portal vein embolization}

ICC may cause biliary obstruction when the tumor grows towards the liver hilum. Biliary drainage may be required in the preoperative setting with resectable disease and in the palliative setting. Biliary drainage aims to improve liver function and increase appetite. ${ }^{69}$ Moreover, preoperative biliary drainage may improve liver regeneration and decrease the risk of postoperative liver failure..$^{70,71}$ The main drawback of biliary drainage is colonization of the bile duct that often results in cholangitis. ${ }^{72}$ Patients with a future liver remnant of at least $50 \%$ should probably undergo a resection without preoperative biliary drainage. ${ }^{73,74}$ Drainage can be performed endoscopically or percutaneously. Biliary drainage can reduce symptoms and improve quality of life in the palliative setting. ${ }^{75,76}$
A resection of more than $75 \%$ of the total liver volume in a healthy liver and more than $65 \%$ of the total liver volume in a compromised liver (eg, due to cirrhosis or fibrosis) is an indication of portal vein embolization (PVE). ${ }^{77} \mathrm{PVE}$ results in hypertrophy of the future liver remnant by preoperatively embolizing the liver that will be resected. ${ }^{77}$ In a total of 1,791 patients with different hepatic tumors, PVE had a technical success of $96.1 \%{ }^{77}$

\section{Surgical management Resection}

Surgical treatment is the only potentially curative treatment in patients with ICC. ICC is an aggressive cancer, when compared to other primary hepatic neoplasms., ${ }^{4,14,58}$ A large study $(n=584)$ demonstrated that even after curative-intent resection, the probability of cure is only about $10 \% .{ }^{78}$ Because of the large size as well as intraductal and periductal spread, major hepatectomies are required to obtain negative resection margins. ${ }^{4}$ With regard to prognosis, resection is only useful when a complete resection (R0) with negative resection margins is anticipated. Moreover, the liver remnant should be adequate in size and function, with or without prior PVE. ${ }^{8,77,79,80}$ Extrahepatic disease, including lymph node metastases beyond the regional basin (N2), is a contraindication for curative-intent surgery. ${ }^{41}$ Multifocal ICC is considered unresectable by some experts. ${ }^{79-83}$ Nevertheless, other experts report favorable long-term outcomes in selected patients with typically two to three lesions, with a 5-year overall survival (OS) of $20 \%{ }^{84,85}$ A 2015 cure model confirms the possibility of cure, albeit at a chance of only $4 \% .{ }^{78}$ Recent studies have reported favorable outcomes of portal vein reconstructions. ${ }^{86-88}$ However, tumor invasion of the main hepatic artery and bilateral hepatic artery involvement remain contraindications for resection in most Western centers. Hepatic artery reconstruction is associated with a high risk of postoperative mortality as well as poor oncologic outcomes. ${ }^{89,90}$

A complete resection of ICC involves an (extended) hemihepatectomy in most (75\%) of patients. Many patients $(25 \%)$ also require a bile duct resection and reconstruction. Morbidity rates are often more than one in five, and mortality rates vary from $1 \%$ to $6 \% .{ }^{8,9,91}$ Intraoperative and postoperative strategies, such as low central venous pressure, restricted fluid resuscitation, and enhanced recovery pathways, have improved recovery and decreased the risk of complications. ${ }^{87,88,92}$ A recent article reviewed perioperative management of patients undergoing hepatic resection..$^{93}$ The authors noted that surgeons left an operative drain in almost half of patients undergoing liver resection, even though most data suggest that routine operative drainage after liver 
resection (without a biliary anastomosis) is unnecessary and should generally be avoided. ${ }^{94-96}$

Whereas HCC is commonly treated with orthotopic liver transplantation (OLT), ICC as an indication for OLT is still controversial. ${ }^{97}$ Historical evidence suggests poor outcomes for ICC in single-center studies ${ }^{98-104}$ Outcomes of OLT for combined HCC and ICC were also predominantly unfavorable. ${ }^{98,105}$ Five-year survival estimates in these studies ranged from $10 \%$ to $18 \%$, which is clearly inferior to the benchmark of OLT of about $70 \% .{ }^{97}$ More recent studies indicate that strictly selected patients might benefit from OLT, particularly patients with ICC smaller than $2 \mathrm{~cm} .{ }^{106}$

\section{Systemic chemotherapy Preoperative chemotherapy}

Preoperative chemotherapy (pCT) can be administered for multiple purposes, although it is not routinely prescribed due to a lack of evidence. ${ }^{107}$ Neoadjuvant therapy is employed to address occult metastatic disease or facilitate resection. We recently evaluated the role of $\mathrm{pCT}$ in a cohort of 1,057 patients, of whom 62 patients received chemotherapy. We found that patients receiving pCT had similar survival following curative-intent resection, regardless of more advanced disease. ${ }^{107}$ No regimen is currently proven to have effect during the preoperative period. In light of the outcomes of the ABC-02 trial, discussed later, a combination of gemcitabine and cisplatin was offered most often. ${ }^{108}$

\section{Adjuvant chemotherapy}

Adjuvant chemotherapy is aimed at decreasing the chance of tumor recurrence. ${ }^{109}$ Chemotherapy consists of mainly nucleoside analogs, most commonly gemcitabine, sometimes in combination with cisplatin. ${ }^{109}$ Systemic therapy is known to have a large impact on patient's quality of life, and form a large financial burden. The efficacy of chemotherapy regimens in ICC is usually poor, with only a small subgroup benefitting significantly in both quality of life and length of survival. ${ }^{16,109}$ While a significant portion of the US patients receive chemotherapy, no randomized trials have been completed. ${ }^{42}$ A multicenter phase III trial is currently accruing patients to determine the effectiveness of adjuvant gemcitabine and cisplatin in patients with biliary cancer (Table 2).

\section{Palliative chemotherapy}

A phase III trial, the ABC-02 trial, randomized 410 patients with biliary cancer (ie, cholangiocarcinoma and gallbladder cancer) and found an improvement in OS of nearly 4 months with gemcitabine plus cisplatin compared to gemcitabine alone. ${ }^{108} \mathrm{~A}$ combined analysis of the $\mathrm{ABC}-02$ trial and the

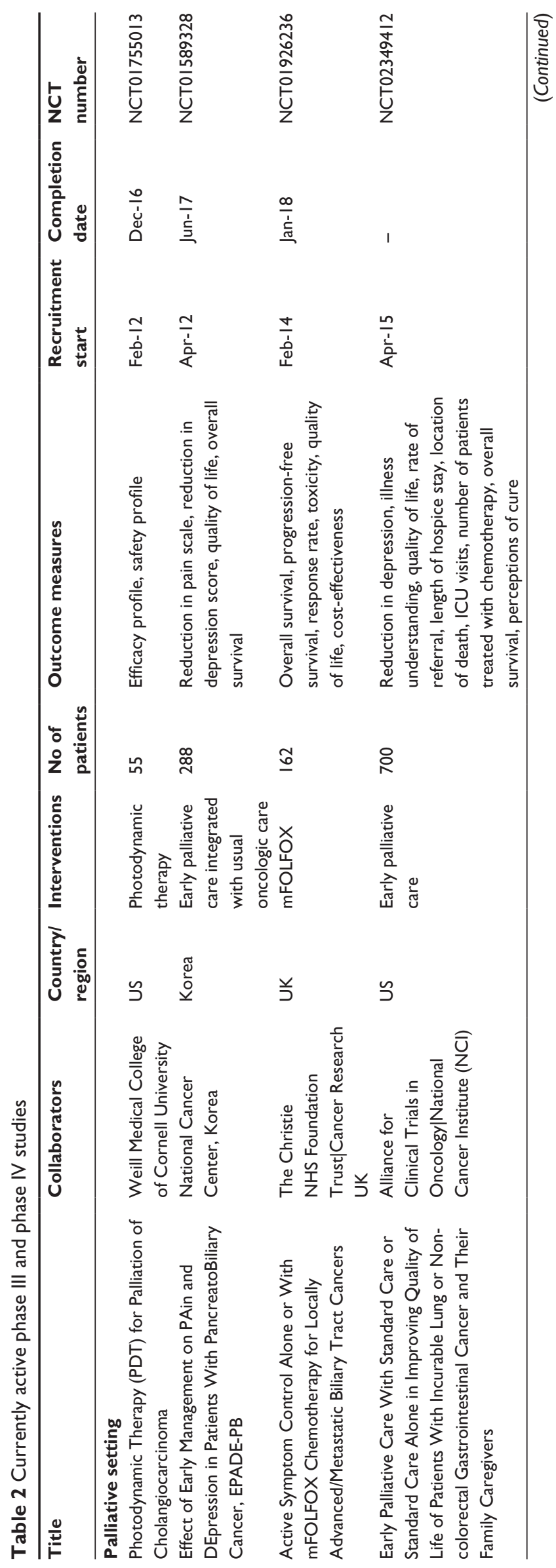




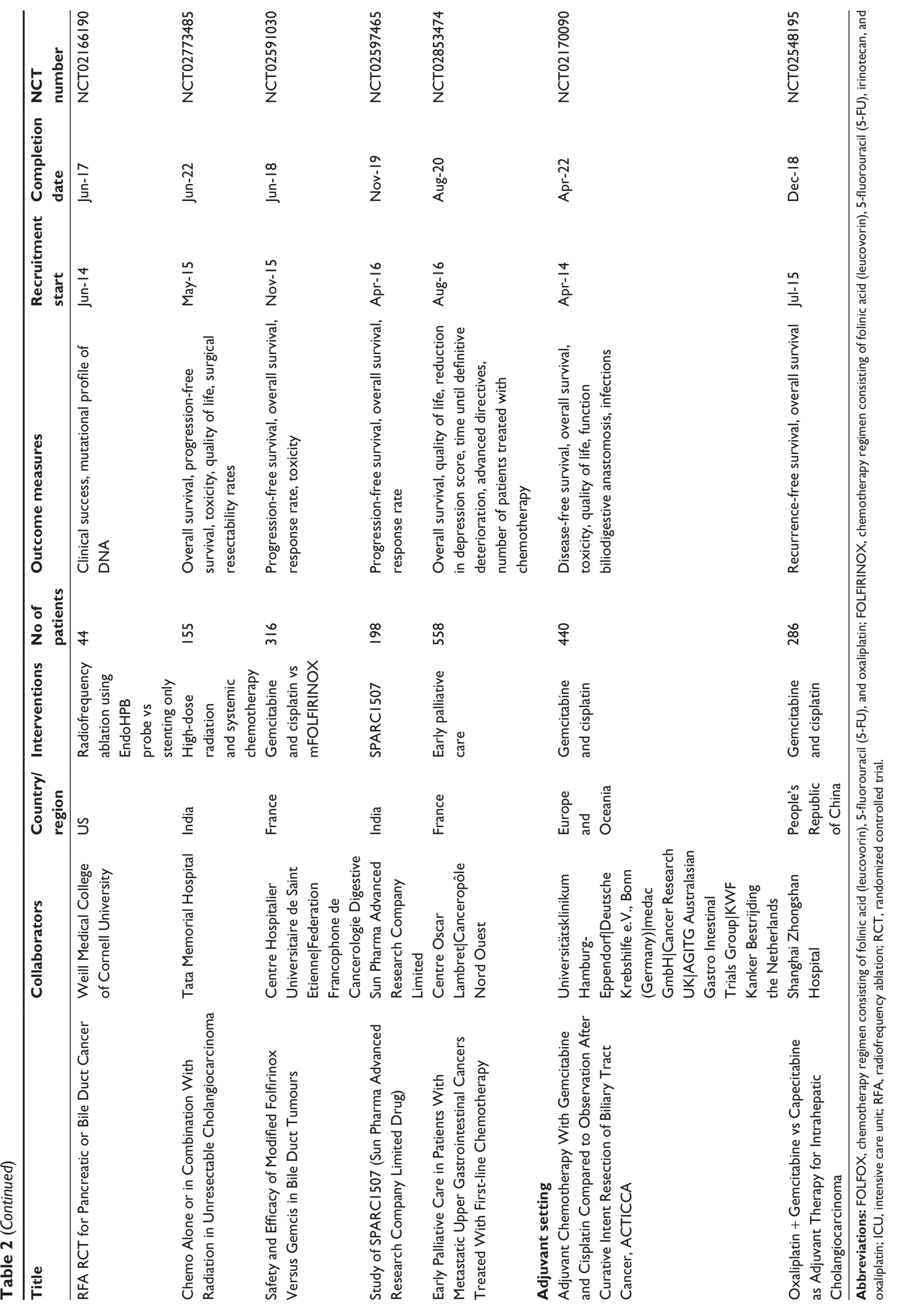


Japanese BT22 trial, conducted in a comparable setting, found a hazard ratio of 0.54 (95\% confidence interval $0.36-0.81)$ for the subgroup of 108 patients with ICC. ${ }^{110}$ Gemcitabine plus cisplatin has been the standard palliative regimen for locally advanced or metastatic ICC since. Best supportive care is recommended for patients with a poor performance status or a life expectancy of less than 6 months. ${ }^{11-114}$

\section{Regional treatments}

Regional treatments rely on the dual blood supply of the liver, where the hepatic artery is mostly responsible for the blood supply of tumors, as illustrated by early arterial enhancement on imaging. ${ }^{15-117}$ Hepatic arterial infusion (HAI) chemotherapy using a subcutaneous pump has been investigated for patients with ICC at Memorial Sloan Kettering Cancer Center (MSKCC). It involves continuous infusion of floxuridine directly into the hepatic artery. Intraarterial delivery allows for a 200 -fold higher drug delivery to the tumor with little systemic toxicity because of the $95 \%$ first-pass effect of floxuridine in the liver. ${ }^{5} \mathrm{HAI}$ chemotherapy has been studied extensively in common malignancies, such as colorectal liver metastases. ${ }^{5,118}$

In a recent study from MSKCC, HAI with floxuridine was combined with systemic chemotherapy in patients with locally advanced (ie, unresectable without extrahepatic disease) ICC $(n=104) .{ }^{5}$ Outcomes were compared with locally advanced patients receiving systemic chemotherapy alone. ${ }^{5}$ Median OS was superior with HAI chemotherapy (30.8 months vs 18.4 months; $P<0.001$ ). Five-year OS was $20 \%$ in patients who received HAI chemotherapy compared with $5 \%$ in the systemic-only group. In comparison, 5-year OS was $0 \%$ in the $\mathrm{ABC}-02$ trial. ${ }^{108}$ Moreover, the partial response rate (RECIST criteria) in the HAI chemotherapy group was $59 \%$, with conversion to resectability in eight of 104 patients $(13 \%)$. Future prospective studies should be conducted in order to confirm these results. Currently, a phase II trial is recruiting patients for HAI chemotherapy in the adjuvant setting (NCT01312857).

Other hepatic artery-based treatments for locally advanced ICC include transarterial chemoembolization (TACE) and radio-embolization with yttrium-90 (Y-90). ${ }^{115}$ TACE affects the blood flow to the tumor in addition to locally releasing cytotoxic agents. It causes ischemic tumor necrosis and facilitates intracellular transit of chemotherapeutic agents. ${ }^{15,117}$ In a study of 41 prospectively followed patients, one group described a median OS of 11.7 months from first treatment, after treatment with irinotecan TACE. ${ }^{119}$ One patient successfully underwent resection following TACE. ${ }^{119}$ Another prospective study reported a median survival of 17.5 months in
24 patients, with three patients being adequately downstaged to undergo resection. ${ }^{120}$ Despite the encouraging results, no phase III trial has been performed. ${ }^{115}$

Y-90 radio-embolization therapy also aims to improve life expectancy in patients with unresectable HCC and colorectal liver metastases. ${ }^{115}$ The technique is based on administration of beads filled with the radioactive isotope yttrium Y-90 microspheres into the hepatic artery branch responsible for the lobes of the liver beset by tumor. ${ }^{121,122}$ Prior to treatment, embolization of the nontarget vessels and injection of technetium-99mm-labeled macro-aggregated albumin is performed, in order to exclude extrahepatic accumulation. ${ }^{115,121,122}$ Several small studies indicate that $\mathrm{Y}-90$ is tolerated well in patients with a good performance status. ${ }^{123-128}$ In ICC patients, Y-90 was associated with improved survival, when compared with patients undergoing best supportive care only. ${ }^{123-128}$ Estimates ranged from 9 months posttreatment in a cohort of 25 Australian patients, ${ }^{127}$ to 22 months in a cohort of 33 German patients. ${ }^{126}$ Randomized trials are required to determine the effectiveness of Y-90 therapy.

\section{Prognostic models and nomograms}

Several prognostic models have been developed in addition to the AJCC staging. More accurate prediction of individual patient outcome may provide better individual survival estimates, as well as improve identification of high-risk groups who may benefit from adjuvant therapy. ${ }^{11}$ While the AJCC staging concerns all ICC patients, other models pertain only to patients who have undergone a complete resection. A Chinese nomogram predicts individual OS after resection of ICC (Figure 3). ${ }^{43}$ Prognostic factors in this model included CEA, CA19-9, vascular invasion, presence of lymph node metastases, direct invasion and local metastases, number of tumors, and tumor diameter. A similar model was developed with a multinational dataset without tumor markers. Risk factors for survival after resection were age, number of tumors, tumor diameter, cirrhosis, lymph node metastases, and macrovascular invasion. ${ }^{129}$ The Chinese nomogram had superior discrimination at external validation. $^{43,44}$

Other prognostic models were developed for conditional survival, accounting for the years that a patient had already survived after surgery. ${ }^{84,130,131}$ Conditional survival was found to be the most important prognostic factor, when predicting future survival time. ${ }^{84,130,131} \mathrm{OS}$ in this study decreased over time to $16 \%$ at 8 years, while the 3 -year conditional survival at 5 years, that is, the chance of surviving to year 8 after having survived to year 5 , was $65 \%{ }^{84}$ 




Figure 3 Validated intrahepatic cholangiocarcinoma nomogram predicting overall survival. Adapted from Wang et al. ${ }^{43}$

Note: Reprinted with permission. (c) 2013. American Society of Clinical Oncology. All rights reserved. Wang Y, Li J, Xia Y, et al, Prognostic nomogram for intrahepatic cholangiocarcinoma after partial hepatectomy, J Clin Oncol. 3I(9): I I88-I I95.43

Abbreviations: CEA, carcino-embryonic antigen; LN, lymph node; PI, periductal invasion.

\section{Personalized treatments}

Personalized treatments for ICC patients could improve the overall outcomes, mainly by withholding treatments from patients who are unlikely to benefit from surgery or chemotherapy. For example, patients with a very poor predicted survival after surgery (eg, 3-year OS below 5\% based on the Chinese nomogram in Figure 3) are unlikely to benefit from surgery. Unfortunately, predictive biomarkers for response to systemic chemotherapy are not available. ${ }^{45}$ Future studies should further improve prognostic models and identify predictive biomarkers to determine the response to chemotherapy. ${ }^{44,132}$

\section{Future perspectives}

ICC is a complex disease, with a dismal prognosis. ICC is typically diagnosed with metastatic or locally advanced disease. Surgery may improve both survival and quality of life, but comes with a substantial risk of postoperative morbidity and mortality. The benefit of palliative systemic treatment is real but small. The merits of (neo)adjuvant therapy still need to be explored in phase III trials. Targeted therapies (eg, targeting IDH 1 or 2 mutations) are promising but require further evaluation. ${ }^{133} \mathrm{HAI}, \mathrm{TACE}$, and radio-embolization are promising locoregional techniques. Appropriate allocation of all locoregional and systemic treatments may further improve with better knowledge of histopathology and biological behavior.
Ideally, low-cost diagnostic biomarkers could reliably detect ICC in patients presenting with vague symptoms of the upper abdomen or screened for liver cancer. Furthermore, predictive biomarkers are required to determine in advance which patients will benefit from chemotherapy.

\section{Disclosure}

The authors report no conflicts of interest in this work.

\section{References}

1. Shin HR, Oh JK, Masuyer E, et al. Comparison of incidence of intrahepatic and extrahepatic cholangiocarcinoma - focus on East and South-Eastern Asia. Asian Pac J Cancer Prev. 2010;11(5): $1159-1166$.

2. Singal AK, Vauthey JN, Grady JJ, Stroehlein JR. Intra-hepatic cholangiocarcinoma - frequency and demographic patterns: thirty-year data from the M.D. Anderson Cancer Center. J Cancer Res Clin Oncol. 2011; 137(7):1071-1078.

3. Everhart JE, Ruhl CE. Burden of digestive diseases in the United States Part III: liver, biliary tract, and pancreas. Gastroenterology. 2009;136(4): 1134-1144.

4. DeOliveira ML, Cunningham SC, Cameron JL, et al. Cholangiocarcinoma: thirty-one-year experience with 564 patients at a single institution. Ann Surg. 2007;245(5):755-762.

5. Konstantinidis IT, Groot Koerkamp B, Do RK, et al. Unresectable intrahepatic cholangiocarcinoma: systemic plus hepatic arterial infusion chemotherapy is associated with longer survival in comparison with systemic chemotherapy alone. Cancer. 2016;122(5):758-765.

6. Esnaola NF, Meyer JE, Karachristos A, Maranki JL, Camp ER, Denlinger CS. Evaluation and management of intrahepatic and extrahepatic cholangiocarcinoma. Cancer. 2016;122(9):1349-1369. 
7. Nakeeb A, Tran KQ, Black MJ, et al. Improved survival in resected biliary malignancies. Surgery. 2002;132(4):555-563; discussion 563-554.

8. Endo I, Gonen M, Yopp AC, et al. Intrahepatic cholangiocarcinoma: rising frequency, improved survival, and determinants of outcome after resection. Ann Surg. 2008;248(1):84-96.

9. de Jong MC, Nathan H, Sotiropoulos GC, et al. Intrahepatic cholangiocarcinoma: an international multi-institutional analysis of prognostic factors and lymph node assessment. J Clin Oncol. 2011;29(23):3140-3145.

10. Amini N, Ejaz A, Spolverato G, Kim Y, Herman JM, Pawlik TM. Temporal trends in liver-directed therapy of patients with intrahepatic cholangiocarcinoma in the United States: a population-based analysis. J Surg Oncol. 2014;110(2):163-170.

11. Tyson GL, El-Serag HB. Risk factors for cholangiocarcinoma. Hepatology. 2011;54(1):173-184.

12. Khan SA, Toledano MB, Taylor-Robinson SD. Epidemiology, risk factors, and pathogenesis of cholangiocarcinoma. HPB (Oxford). 2008;10(2):77-82.

13. Brito AF, Abrantes AM, Encarnacao JC, Tralhão JG, Botelho MF. Cholangiocarcinoma: from molecular biology to treatment. Med Oncol. 2015;32(11):245.

14. Dodson RM, Weiss MJ, Cosgrove D, et al. Intrahepatic cholangiocarcinoma: management options and emerging therapies. J Am Coll Surg. 2013;217(4):736-750.e4.

15. Casper FW, Seufert RJ. Atrial natriuretic peptide (ANP) in preeclampsia-like syndrome in a rat model. Exp Clin Endocrinol Diabetes. 1995;103(5):292-296.

16. Anderson CD, Pinson CW, Berlin J, Chari RS. Diagnosis and treatment of cholangiocarcinoma. Oncologist. 2004;9(1):43-57.

17. Olnes MJ, Erlich R. A review and update on cholangiocarcinoma Oncology. 2004;66(3):167-179.

18. Nakanuma Y, Sato Y, Harada K, Sasaki M, Xu J, Ikeda H. Pathological classification of intrahepatic cholangiocarcinoma based on a new concept. World J Hepatol. 2010;2(12):419-427.

19. O’Dell MR, Huang JL, Whitney-Miller CL, et al. Kras(G12D) and p53 mutation cause primary intrahepatic cholangiocarcinoma. Cancer Res. 2012;72(6):1557-1567.

20. Fava G, Lorenzini I. Molecular pathogenesis of cholangiocarcinoma. Int J Hepatol. 2012;2012:630543.

21. Johnson C, Han Y, Hughart N, McCarra J, Alpini G, Meng F. Interleukin-6 and its receptor, key players in hepatobiliary inflammation and cancer. Transl Gastrointest Cancer. 2012;1(1):58-70.

22. Goydos JS, Brumfield AM, Frezza E, Booth A, Lotze MT, Carty SE. Marked elevation of serum interleukin-6 in patients with cholangiocarcinoma: validation of utility as a clinical marker. Ann Surg. 1998;227(3):398-404.

23. Lee KH, Lee KB, Kim TY, et al. Clinical and pathological significance of ROS1 expression in intrahepatic cholangiocarcinoma. BMC Cancer. 2015;15:721

24. Deng G, Hu C, Zhu L, et al. Downregulation of ROS-FIG inhibits cell proliferation, colonyformation, cell cycle progression, migration and invasion, while inducing apoptosis in intrahepatic cholangiocarcinoma cells. Int J Mol Med. 2014;34(3):661-668.

25. Lazaridis KN, Gores GJ. Cholangiocarcinoma. Gastroenterology. 2005; 128(6):1655-1667.

26. Chung YE, Kim MJ, Park YN, et al. Varying appearances of cholangiocarcinoma: radiologic-pathologic correlation. Radiographics. 2009;29(3):683-700.

27. Kang Y, Lee JM, Kim SH, Han JK, Choi BI. Intrahepatic mass-forming cholangiocarcinoma: enhancement patterns on gadoxetic acid-enhanced MR images. Radiology. 2012;264(3):751-760.

28. Okabayashi T, Yamamoto J, Kosuge T, et al. A new staging system for mass-forming intrahepatic cholangiocarcinoma: analysis of preoperative and postoperative variables. Cancer. 2001;92(9):2374-2383.

29. Kim SJ, Lee JM, Han JK, Kim KH, Lee JY, Choi BI. Peripheral massforming cholangiocarcinoma in cirrhotic liver. AJR Am J Roentgenol. 2007;189(6):1428-1434.
30. Mamone G, Marrone G, Caruso S, et al. Intrahepatic mass-forming cholangiocarcinoma: enhancement pattern on Gd-BOPTA-MRI with emphasis of hepatobiliary phase. Abdom Imaging. 2015;40(7):2313-2322.

31. Lim JH. Cholangiocarcinoma: morphologic classification according to growth pattern and imaging findings. AJR Am J Roentgenol. 2003; 181(3):819-827.

32. Lim JH, Yi CA, Lim HK, Lee WJ, Lee SJ, Kim SH. Radiological spectrum of intraductal papillary tumors of the bile ducts. Korean J Radiol. 2002; 3(1):57-63.

33. Mittelstaedt CA. Ultrasound of the bile ducts. Semin Roentgenol. 1997; 32(3):161-171.

34. Park HS, Lee JM, Kim SH, et al. CT differentiation of cholangiocarcinoma from periductal fibrosis in patients with hepatolithiasis. AJR Am J Roentgenol. 2006;187(2):445-453.

35. Lim JH, Park CK. Pathology of cholangiocarcinoma. Abdom Imaging 2004;29(5):540-547.

36. Sasaki A, Aramaki M, Kawano K, et al. Intrahepatic peripheral cholangiocarcinoma: mode of spread and choice of surgical treatment. Br J Surg. 1998;85(9):1206-1209.

37. Jarnagin WR, Weber S, Tickoo SK, et al. Combined hepatocellular and cholangiocarcinoma: demographic, clinical, and prognostic factors. Cancer. 2002;94(7):2040-2046.

38. Maximin S, Ganeshan DM, Shanbhogue AK, et al. Current update on combined hepatocellular-cholangiocarcinoma. Eur J Radiol Open. 2014;1:40-48.

39. Wu PC, Fang JW, Lau VK, Lai CL, Lo CK, Lau JY. Classification of hepatocellular carcinoma according to hepatocellular and biliary differentiation markers. Clinical and biological implications. Am J Pathol. 1996;149(4):1167-1175.

40. Woo HG, Lee JH, Yoon JH, et al. Identification of a cholangiocarcinomalike gene expression trait in hepatocellular carcinoma. Cancer Res. 2010;70(8):3034-3041.

41. Edge SB, Byrd DR, Compton CC, Fritz AG, Greene FL, Trotti A. AJCC Cancer Staging Manual. 7th ed. Paris: Springer; 2010.

42. Weber SM, Ribero D, O’Reilly EM, Kokudo N, Miyazaki M, Pawlik TM. Intrahepatic cholangiocarcinoma: expert consensus statement. $H P B$ (Oxford). 2015;17(8):669-680.

43. Wang Y, Li J, Xia Y, et al. Prognostic nomogram for intrahepatic cholangiocarcinoma after partial hepatectomy. J Clin Oncol. 2013;31(9): 1188-1195.

44. Doussot A, Groot-Koerkamp B, Wiggers JK, et al. Outcomes after resection of intrahepatic cholangiocarcinoma: external validation and comparison of prognostic models. J Am Coll Surg. 2015;221(2): $452-461$.

45. Ruys AT, Groot Koerkamp B, Wiggers JK, Klümpen HJ, ten Kate FJ, van Gulik TM. Prognostic biomarkers in patients with resected cholangiocarcinoma: a systematic review and meta-analysis. Ann Surg Oncol. 2014;21(2):487-500.

46. Wiggers JK, Ruys AT, Groot Koerkamp B, Beuers U, ten Kate FJ, van Gulik TM. Differences in immunohistochemical biomarkers between intra- and extrahepatic cholangiocarcinoma: a systematic review and meta-analysis. J Gastroenterol Hepatol. 2014;29(8):1582-1594.

47. Bridgewater J, Galle PR, Khan SA, et al. Guidelines for the diagnosis and management of intrahepatic cholangiocarcinoma. J Hepatol. 2014; 60(6):1268-1289.

48. Sia D, Hoshida Y, Villanueva A, et al. Integrative molecular analysis of intrahepatic cholangiocarcinoma reveals 2 classes that have different outcomes. Gastroenterology. 2013;144(4):829-840.

49. Iguchi T, Aishima S, Taketomi A, et al. Fascin overexpression is involved in carcinogenesis and prognosis of human intrahepatic cholangiocarcinoma: immunohistochemical and molecular analysis. Hum Pathol. 2009;40(2):174-180.

50. Shafizadeh N, Grenert JP, Sahai V, Kakar S. Epidermal growth factor receptor and HER-2/neu status by immunohistochemistry and fluorescence in situ hybridization in adenocarcinomas of the biliary tree and gallbladder. Hum Pathol. 2010;41(4):485-492. 
51. Herberger B, Berger W, Puhalla H, et al. Simultaneous blockade of the epidermal growth factor receptor/mammalian target of rapamycin pathway by epidermal growth factor receptor inhibitors and rapamycin results in reduced cell growth and survival in biliary tract cancer cells. Mol Cancer Ther. 2009;8(6):1547-1556.

52. Higashi M, Yamada N, Yokoyama S, et al. Pathobiological implications of MUC16/CA125 expression in intrahepatic cholangiocarcinoma-mass forming type. Pathobiology. 2012;79(2):101-106.

53. Park SY, Roh SJ, Kim YN, et al. Expression of MUC1, MUC2, MUC5AC and MUC6 in cholangiocarcinoma: prognostic impact. Oncol Rep. 2009;22(3):649-657.

54. Yeh CN, Pang ST, Wu RC, Chen TW, Jan YY, Chen MF. Prognostic value of MUC4 for mass-forming intrahepatic cholangiocarcinoma after hepatectomy. Oncol Rep. 2009;21(1):49-56.

55. Hashimoto N, Yachida S, Okano K, et al. Immunohistochemically detected expression of p27(Kip1) and Skp2 predicts survival in patients with intrahepatic cholangiocarcinomas. Ann Surg Oncol. 2009; 16(2):395-403.

56. Jarnagin WR, Klimstra DS, Hezel M, et al. Differential cell cycleregulatory protein expression in biliary tract adenocarcinoma: correlation with anatomic site, pathologic variables, and clinical outcome. J Clin Oncol. 2006;24(7):1152-1160.

57. Fiorentino M, Altimari A, D'Errico A, et al. Low p27 expression is an independent predictor of survival for patients with either hilar or peripheral intrahepatic cholangiocarcinoma. Clin Cancer Res. 2001; 7(12):3994-3999.

58. Razumilava N, Gores GJ. Cholangiocarcinoma. Lancet. 2014;383(9935): 2168-2179.

59. Brown KM, Parmar AD, Geller DA. Intrahepatic cholangiocarcinoma. Surg Oncol Clin N Am. 2014;23(2):231-246.

60. Netherlands Comprehensive Cancer Organisation. Oncoline: Clinical practice guidelines. Available from: http://www.oncoline.nl/. Accessed August 10, 2016.

61. Valls C, Guma A, Puig I, et al. Intrahepatic peripheral cholangiocarcinoma: CT evaluation. Abdom Imaging. 2000;25(5):490-496.

62. Weber A, Schmid RM, Prinz C. Diagnostic approaches for cholangiocarcinoma. World J Gastroenterol. 2008;14(26):4131-4136.

63. Suthar M, Purohit S, Bhargav V, Goyal P. Role of MRCP in differentiation of benign and malignant causes of biliary obstruction. J Clin Diagn Res. 2015;9(11):TC08-TC12.

64. Anderson CD, Rice MH, Pinson CW, Chapman WC, Chari RS, Delbeke D. Fluorodeoxyglucose PET imaging in the evaluation of gallbladder carcinoma and cholangiocarcinoma. J Gastrointest Surg. 2004;8(1):90-97.

65. Kim YJ, Yun M, Lee WJ, Kim KS, Lee JD. Usefulness of 18F-FDG PET in intrahepatic cholangiocarcinoma. Eur J Nucl Med Mol Imaging. 2003;30(11):1467-1472.

66. Corvera CU, Blumgart LH, Akhurst T, et al. 18F-fluorodeoxyglucose positron emission tomography influences management decisions in patients with biliary cancer. J Am Coll Surg. 2008;206(1):57-65.

67. Weber SM, Jarnagin WR, Klimstra D, DeMatteo RP, Fong Y, Blumgart LH. Intrahepatic cholangiocarcinoma: resectability, recurrence pattern, and outcomes. J Am Coll Surg. 2001;193(4):384-391.

68. Goere D, Wagholikar GD, Pessaux P, et al. Utility of staging laparoscopy in subsets of biliary cancers: laparoscopy is a powerful diagnostic tool in patients with intrahepatic and gallbladder carcinoma. Surg Endosc. 2006;20(5):721-725.

69. van der Gaag NA, Kloek JJ, de Castro SM, Busch OR, van Gulik TM, Gouma DJ. Preoperative biliary drainage in patients with obstructive jaundice: history and current status. J Gastrointest Surg. 2009;13(4): 814-820.

70. Nimura Y. Preoperative biliary drainage before resection for cholangiocarcinoma (Pro). HPB (Oxford). 2008;10(2):130-133.

71. Kawasaki S, Imamura H, Kobayashi A, Noike T, Miwa S, Miyagawa S. Results of surgical resection for patients with hilar bile duct cancer: application of extended hepatectomy after biliary drainage and hemihepatic portal vein embolization. Ann Surg. 2003;238(1):84-92.
72. Iacono C, Ruzzenente A, Campagnaro T, Bortolasi L, Valdegamberi A, Guglielmi A. Role of preoperative biliary drainage in jaundiced patients who are candidates for pancreatoduodenectomy or hepatic resection: highlights and drawbacks. Ann Surg. 2013;257(2):191-204.

73. Wiggers JK, Groot Koerkamp B, Cieslak KP, et al. Postoperative mortality after liver resection for perihilar cholangiocarcinoma: development of a risk score and importance of biliary drainage of the future liver remnant. J Am Coll Surg. 2016;223(2):321-331.e1.

74. Farges O, Regimbeau JM, Fuks D, et al. Multicentre European study of preoperative biliary drainage for hilar cholangiocarcinoma. Br J Surg. 2013;100(2):274-283.

75. van Delden OM, Laméris JS. Percutaneous drainage and stenting for palliation of malignant bile duct obstruction. Eur Radiol. 2008;18(3): 448-456.

76. Gamanagatti S, Singh T, Sharma R, Srivastava DN, Dash NR, Garg PK. Unilobar versus bilobar biliary drainage: effect on quality of life and bilirubin level reduction. Indian J Palliat Care. 2016;22(1):50-62.

77. van Lienden KP, van den Esschert JW, de Graaf W, et al. Portal vein embolization before liver resection: a systematic review. Cardiovasc Intervent Radiol. 2013;36(1):25-34.

78. Spolverato G, Vitale A, Cucchetti A, et al. Can hepatic resection provide a long-term cure for patients with intrahepatic cholangiocarcinoma? Cancer. 2015;121(22):3998-4006.

79. Ribero D, Pinna AD, Guglielmi A, et al. Surgical approach for longterm survival of patients with intrahepatic cholangiocarcinoma: a multi-institutional analysis of 434 patients. Arch Surg. 2012;147(12): $1107-1113$

80. Hyder O, Hatzaras I, Sotiropoulos GC, et al. Recurrence after operative management of intrahepatic cholangiocarcinoma. Surgery. 2013; 153(6):811-818.

81. Luo X, Yuan L, Wang Y, Ge R, Sun Y, Wei G. Survival outcomes and prognostic factors of surgical therapy for all potentially resectable intrahepatic cholangiocarcinoma: a large single-center cohort study. J Gastrointest Surg. 2014;18(3):562-572.

82. Sulpice L, Rayar M, Boucher E, Pracht M, Meunier B, Boudjema K. Treatment of recurrent intrahepatic cholangiocarcinoma. Br J Surg. 2012;99(12):1711-1717.

83. Farges O, Fuks D, Boleslawski E, et al. Influence of surgical margins on outcome in patients with intrahepatic cholangiocarcinoma: a multicenter study by the AFC-IHCC-2009 study group. Ann Surg. 2011;254(5):824-829; discussion 830.

84. Spolverato G, Kim Y, Ejaz A, et al. Conditional probability of long-term survival after liver resection for intrahepatic cholangiocarcinoma: a multi-institutional analysis of 535 patients. JAMA Surg. 2015;150(6):538-545.

85. Spolverato G, Kim Y, Alexandrescu S, et al. Is hepatic resection for large or multifocal intrahepatic cholangiocarcinoma justified? Results from a multi-institutional collaboration. Ann Surg Oncol. 2015;22(7): 2218-2225.

86. Amini N, Spolverato G, Kim Y, Pawlik TM. Trends in hospital volume and failure to rescue for pancreatic surgery. J Gastrointest Surg. 2015; 19(9):1581-1592.

87. Gurusamy KS, Li J, Vaughan J, Sharma D, Davidson BR. Cardiopulmonary interventions to decrease blood loss and blood transfusion requirements for liver resection. Cochrane Database Syst Rev. 2012;(5):CD007338.

88. Kim Y, Ejaz A, Gani F, et al. Crystalloid administration among patients undergoing liver surgery: defining patient- and provider-level variation. Surgery. 2016;159(2):389-398.

89. Hartog H, Ijzermans JN, van Gulik TM, Groot Koerkamp B. Resection of perihilar cholangiocarcinoma. Surg Clin North Am. 2016;96(2): $247-267$.

90. Abbas S, Sandroussi C. Systematic review and meta-analysis of the role of vascular resection in the treatment of hilar cholangiocarcinoma. HPB (Oxford). 2013;15(7):492-503.

91. Giuliante F, Gauzolino R, Vellone M, Ardito F, Murazio M, Nuzzo G. Liver resection for intrahepatic cholangiocarcinoma. Tumori. 2005; 91(6):487-492. 
92. Gurusamy KS, Li J, Sharma D, Davidson BR. Cardiopulmonary interventions to decrease blood loss and blood transfusion requirements for liver resection. Cochrane Database Syst Rev. 2009;(4):CD007338.

93. Spolverato G, Ejaz A, Kim Y, et al. Patterns of care among patients undergoing hepatic resection: a query of the National Surgical Quality Improvement Program-targeted hepatectomy database. J Surg Res. 2015; 196(2):221-228.

94. Fong Y, Brennan MF, Brown K, Heffernan N, Blumgart LH. Drainage is unnecessary after elective liver resection. Am J Surg. 1996;171(1): $158-162$.

95. Butte JM, Grendar J, Bathe O, et al. The role of peri-hepatic drain placement in liver surgery: a prospective analysis. HPB (Oxford). 2014; 16(10):936-942.

96. Brooke-Smith M, Figueras J, Ullah S, et al. Prospective evaluation of the International Study Group for Liver Surgery definition of bile leak after a liver resection and the role of routine operative drainage: an international multicentre study. HPB (Oxford). 2015;17(1):46-51.

97. Sapisochin G, Fernández de Sevilla E, Echeverri J, Charco R. Liver transplantation for cholangiocarcinoma: current status and new insights. World J Hepatol. 2015;7(22):2396-2403.

98. DeOliveira ML. Liver transplantation for cholangiocarcinoma: current best practice. Curr Opin Organ Transplant. 2014;19(3):245-252.

99. Robles R, Figueras J, Turrion VS, et al. Spanish experience in liver transplantation for hilar and peripheral cholangiocarcinoma. Ann Surg 2004;239(2):265-271.

100. Casavilla FA, Marsh JW, Iwatsuki S, et al. Hepatic resection and transplantation for peripheral cholangiocarcinoma. J Am Coll Surg. 1997;185(5):429-436.

101. Jan YY, Yeh CN, Yeh TS, Chen TC. Prognostic analysis of surgical treatment of peripheral cholangiocarcinoma: two decades of experience at Chang Gung Memorial Hospital. World J Gastroenterol. 2005;11(12):1779-1784.

102. Meyer CG, Penn I, James L. Liver transplantation for cholangiocarcinoma: results in 207 patients. Transplantation. 2000;69(8) $1633-1637$.

103. Ghali P, Marotta PJ, Yoshida EM, et al. Liver transplantation for incidental cholangiocarcinoma: analysis of the Canadian experience. Liver Transpl. 2005;11(11):1412-1416.

104. Weimann A, Varnholt H, Schlitt HJ, et al. Retrospective analysis of prognostic factors after liver resection and transplantation for cholangiocellular carcinoma. Br J Surg. 2000;87(9):1182-1187.

105. Groeschl RT, Pappas SG, Christians KK, et al. Are we justified in excluding combined hepatocellular-cholangiocarcinoma from transplantation? J Clin Oncol. 2012;30(Suppl 4):256.

106. Rizvi S, Gores GJ. Pathogenesis, diagnosis, and management of cholangiocarcinoma. Gastroenterology. 2013;145(6):1215-1229.

107. Buettner S, Groot Koerkamp B, Ejaz A, et al. The effect of preoperative chemotherapy treatment in surgically treated intrahepatic cholangiocarcinoma patients - a multi-institutional analysis. J Surg Oncol. In press 2016

108. Valle J, Wasan H, Palmer DH, et al; ABC-02 Trial Investigators. Cisplatin plus gemcitabine versus gemcitabine for biliary tract cancer. N Engl J Med. 2010;362(14):1273-1281.

109. Horgan AM, Amir E, Walter T, Knox JJ. Adjuvant therapy in the treatment of biliary tract cancer: a systematic review and meta-analysis. J Clin Oncol. 2012;30(16):1934-1940.

110. Valle JW, Furuse J, Jitlal M, et al. Cisplatin and gemcitabine for advanced biliary tract cancer: a meta-analysis of two randomised trials. Ann Oncol. 2014;25(2):391-398.

111. Goenka MK, Goenka U. Palliation: hilar cholangiocarcinoma. World J Hepatol. 2014;6(8):559-569.

112. Taylor MC, McLeod RS, Langer B. Biliary stenting versus bypass surgery for the palliation of malignant distal bile duct obstruction: a meta-analysis. Liver Transpl. 2000;6(3):302-308.

113. Smith AC, Dowsett JF, Russell RC, Hatfield AR, Cotton PB. Randomised trial of endoscopic stenting versus surgical bypass in malignant low bileduct obstruction. Lancet. 1994;344(8938):1655-1660.
114. Andersen JR, Sørensen SM, Kruse A, Rokkjaer M, Matzen P. Randomised trial of endoscopic endoprosthesis versus operative bypass in malignant obstructive jaundice. Gut. 1989;30(8):1132-1135.

115. Seidensticker R, Ricke J, Seidensticker M. Integration of chemoembolization and radioembolization into multimodal treatment of cholangiocarcinoma. Best Pract Res Clin Gastroenterol. 2015;29(2): 319-332.

116. Breedis C, Young G. The blood supply of neoplasms in the liver. Am J Pathol. 1954;30(5):969-977.

117. Llovet JM, Real MI, Montana X, et al. Arterial embolisation or chemoembolisation versus symptomatic treatment in patients with unresectable hepatocellular carcinoma: a randomised controlled trial. Lancet. 2002;359(9319):1734-1739.

118. McAuliffe JC, Qadan M, D'Angelica MI. Hepatic resection, hepatic arterial infusion pump therapy, and genetic biomarkers in the management of hepatic metastases from colorectal cancer. $J$ Gastrointest Oncol. 2015;6(6):699-708.

119. Kuhlmann JB, Euringer W, Spangenberg HC, et al. Treatment of unresectable cholangiocarcinoma: conventional transarterial chemoembolization compared with drug eluting bead-transarterial chemoembolization and systemic chemotherapy. Eur J Gastroenterol Hepatol. 2012;24(4):437-443.

120. Schiffman SC, Metzger T, Dubel G, et al. Precision hepatic arterial irinotecan therapy in the treatment of unresectable intrahepatic cholangiocellular carcinoma: optimal tolerance and prolonged overall survival. Ann Surg Oncol. 2011;18(2):431-438.

121. Seidensticker R, Denecke T, Kraus P, et al. Matched-pair comparison of radioembolization plus best supportive care versus best supportive care alone for chemotherapy refractory liver-dominant colorectal metastases. Cardiovasc Intervent Radiol. 2012;35(5):1066-1073.

122. Sangro B, Carpanese L, Cianni R, et al; European Network on Radioembolization with Yttrium-90 Resin Microspheres (ENRY). Survival after yttrium-90 resin microsphere radioembolization of hepatocellular carcinoma across Barcelona clinic liver cancer stages: a European evaluation. Hepatology. 2011;54(3):868-878.

123. Camacho JC, Kokabi N, Xing M, Prajapati HJ, El-Rayes B, Kim HS Modified response evaluation criteria in solid tumors and European Association for the Study of the Liver criteria using delayed-phase imaging at an early time point predict survival in patients with unresectable intrahepatic cholangiocarcinoma following yttrium-90 radioembolization. J Vasc Interv Radiol. 2014;25(2):256-265.

124. Mouli S, Memon K, Baker T, et al. Yttrium-90 radioembolization for intrahepatic cholangiocarcinoma: safety, response, and survival analysis. J Vasc Interv Radiol. 2013;24(8):1227-1234

125. Rafi S, Piduru SM, El-Rayes B, et al. Yttrium-90 radioembolization for unresectable standard-chemorefractory intrahepatic cholangiocarcinoma: survival, efficacy, and safety study. Cardiovasc Intervent Radiol. 2013;36(2):440-448.

126. Hoffmann RT, Paprottka PM, Schön A, et al. Transarterial hepatic yttrium-90 radioembolization in patients with unresectable intrahepatic cholangiocarcinoma: factors associated with prolonged survival. Cardiovasc Intervent Radiol. 2012;35(1):105-116.

127. Saxena A, Bester L, Chua TC, Chu FC, Morris DL. Yttrium-90 radiotherapy for unresectable intrahepatic cholangiocarcinoma: a preliminary assessment of this novel treatment option. Ann Surg Oncol. 2010;17(2):484-491.

128. Ibrahim SM, Mulcahy MF, Lewandowski RJ, et al. Treatment of unresectable cholangiocarcinoma using yttrium-90 microspheres: results from a pilot study. Cancer. 2008;113(8):2119-2128.

129. Hyder O, Marques H, Pulitano C, et al. A nomogram to predict longterm survival after resection for intrahepatic cholangiocarcinoma: an Eastern and Western experience. JAMA Surg. 2014;149(5): 432-438.

130. Kim Y, Ejaz A, Spolverato G, et al. Conditional survival after surgical resection of gastric cancer: a multi-institutional analysis of the US Gastric Cancer Collaborative. Ann Surg Oncol. 2015;22(2): 557-564. 
131. Nathan H, de Jong MC, Pulitano C, et al. Conditional survival after surgical resection of colorectal liver metastasis: an international multiinstitutional analysis of 949 patients. J Am Coll Surg. 2010;210(5): 755-764, 764-766.

132. Groot Koerkamp B, Fong Y. Outcomes in biliary malignancy. J Surg Oncol. 2014;110(5):585-591.
133. Merla A, Liu KG, Rajdev L. Targeted therapy in biliary tract cancers. Curr Treat Options Oncol. 2015;16(10):48.

134. Blechacz B, Komuta M, Roskams T, Gores GJ. Clinical diagnosis and staging of cholangiocarcinoma. Nat Rev Gastroenterol Hepatol. 2011;8(9):512-522.

\section{Publish your work in this journal}

OncoTargets and Therapy is an international, peer-reviewed, open access journal focusing on the pathological basis of all cancers, potential targets for therapy and treatment protocols employed to improve the management of cancer patients. The journal also focuses on the impact of management programs and new therapeutic agents and protocols on

\section{Dovepress}

patient perspectives such as quality of life, adherence and satisfaction. The manuscript management system is completely online and includes a very quick and fair peer-review system, which is all easy to use. Visit http://www.dovepress.com/testimonials.php to read real quotes from published authors. 